\title{
THE VARIABILITY OF VENTRICULAR POTENTIALS AT THE DIAPHRAGMATIC LEVEL OF THE CESOPHAGUS
}

\author{
BY
}

\author{
IRVING G. KROOP,* MORRIS F. STEINBERG, AND ARTHUR GRISHMAN
}

From the Cardiographic Department and Cardiovascular Research Group, The Mount Sinai Hospital, New York

Received August 4, 1950

The use of œsophageal electrocardiograms has been of value for semi-direct exploration of the electrical potentials derived from the posterior surface of the heart. Lieberson and Liberson (1934) reintroduced the method of œsophageal electrocardiography and described a qRs pattern that was considered a derivation from the posterior wall of the left ventricle. These observations were extended by. Brown (1936) in an extensive study of the distribution of cardiac potentials in the œsophagus. In a review of the anatomy of the œsophagus, it was indicated that only a small segment of the lower part of the asophagus at the level of the diaphragm was in relation to the " posterior basal surface of the left ventricle." Fluoroscopic control was considered to be essential in the positioning of the lowermost electrode at the ventricular level. Characteristically, the left ventricular surface pattern of a qRs was obtained at this level. The $P$ wave was ill-defined and slurred and had lost the sharp intrinsic deflection that was characteristic of the $P$ wave at the left atrial levels. Based on the premise that the posterior wall of the left ventricle could thus be explored, Hamilton and Nyboer (1938), and then Nyboer $(1930,1941,1946)$ recommended the osophageal lead for the diagnosis of posterior wall infarction. The " ventricular level " was judged by passing the œsophageal electrode a distance of 45 to $55 \mathrm{~cm}$. from the nares or by the absence of the " auricular $P$ wave" or by both these considerations. The presence of a deep Q and inverted T, wave at the ventricular level was considered characteristic of posterior wall infarction. However, Helm et al. (1944) had difficulty in interpreting ventricular potentials at the lower end of the osophagus, particularly with respect to the $Q$ wave. They found that an endocardial potential like that normally recorded in the œsophagus at left atrial levels could extend to the ventricular level at the diaphragm. In this instance, the $\mathrm{Q}$ wave of endocardial origin would be a normal finding. Recently Burchell (1948) published data that also questioned the value of the osophageal lead in the diagnosis of healed posterior wall infarction. Not only was it difficult to interpret the deep $Q$ and inverted $T$ waves at the level of the left ventricle, but a variety of electrocardiographic patterns were recorded at this level.

During an intensive study of intracardiac potentials in humans, conducted at the Mount Sinai Hospital for the past three years, a large number of patients with normal and abnormal electrocardiograms were studied. Esophageal leads obtained in these patients revealed considerable variability of the ventricular complexes at the diaphragmatic level of the osophagus-the so-called "ventricular level." From this large series of cases, several were selected because they illustrated the variability of the ventricular complex at the "ventricular level," and because they demonstrated the possibility of an erroneous interpretation of a deep $Q$ wave. The findings in these selected cases were suitable to emphasize that the diaphragmatic segment of the œsophagus might often be in closer contact with the inferior vena cava, or the posterior caudad segment of the right atrium, than with the posterior basal wall of the left ventricle.

* Sara Welt and Dazian Fellow in Medicine, The Mount Sinai Hospital, New York. 


\section{METHOD}

Serial œsophageal leads were obtained with a specially constructed œsophageal tube with 15 equidistant electrodes $(1.75 \mathrm{~cm}$. apart). The lowermost electrode was placed fluoroscopically at the diaphragmatic level (E1). A permanent record was obtained by means of a spot-film. Both intracardiac and præcordial reference leads were recorded simultaneously. The Sanborn tri-beam electrocardiograph was used in these studies.

\section{RESULTS}

\section{Patients with Normal Hearts and Normal Electrocardiograms}

Case 1. A man, 35 years of age, had a normal electrocardiogram, including extremity and chest leads. The ventricular complex at E1 $(2.5 \mathrm{~cm}$. below the level of the diaphragm) consisted of a $\mathrm{rSR}^{\prime}$ which was similar to the potential recorded in the right atrium in the region of the inferior vena cava. The $P$ wave at $E 1$ was ill-defined and lacked the intrinsic deflection, which was obtained at E4 over atrial levels (Fig. 1).

The positioning of E1 at the diaphragm and the absence of the intrinsic deflection in the $P$ wave met the requirements of earlier workers for a true " ventricular level." Yet, at this "ventricular
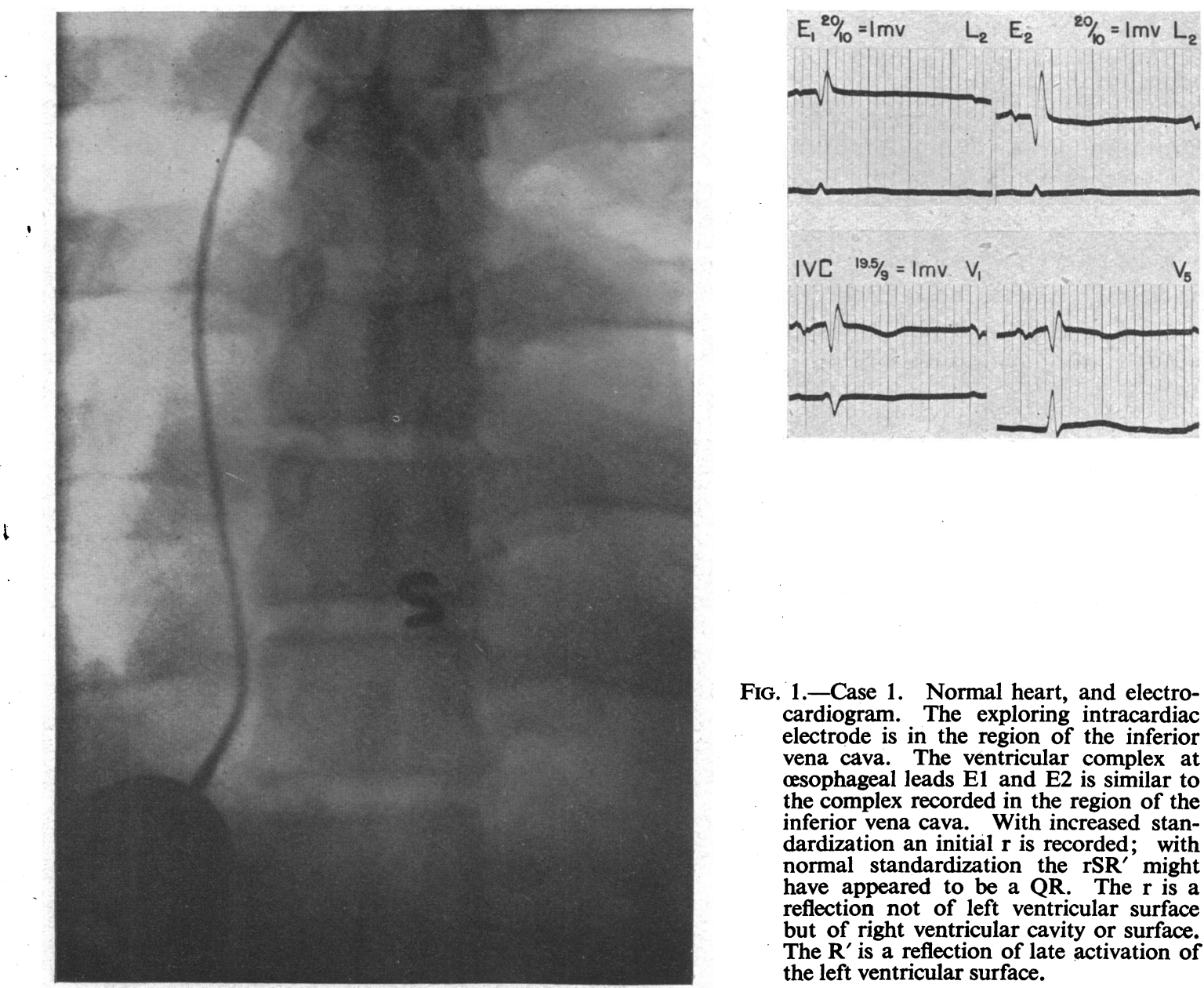

Fig. 1.-Case 1. Normal heart, and electrocardiogram. The exploring intracardiac electrode is in the region of the inferior vena cava. The ventricular complex at osophageal leads E1 and E2 is similar to the complex recorded in the region of the inferior vena cava. With increased standardization an initial $\mathbf{r}$ is recorded; with normal standardization the $\mathrm{rSR}^{\prime}$ might have appeared to be a $Q R$. The $r$ is a reflection not of left ventricular surface but of right ventricular cavity or surface. The $R^{\prime}$ is a reflection of late activation of the left ventricular surface. 
level " and at the inferior vena cava an rSR' was recorded which did not resemble the potentials usually derived from the free surface of the left ventricle (qRs). The rSR' at the inferior vena cava and at E1 represented either right ventricular surface or cavity potential (rS) influenced in its terminal portion by left ventricular surface potential $\left(R^{\prime}\right)$. Furthermore, the $r$ of the $r S R^{\prime}$ paitern was visualized only because standardization was twice the normal $(1 \mathrm{mv}=20 \mathrm{~mm}$.). With normal standardization $\left(1 \mathrm{mv}=10 \mathrm{~mm}\right.$.), the $\mathrm{r}$ would have been almost isoelectric and thus the $\mathrm{rSR}^{\prime}$ could have been mistaken for a $Q R$.

Case 2. A woman, 19 years of age, had a normal electrocardiogram including extremity and chest leads. The ventricular complex at E1 (at the diaphragm) was essentially a W shaped complex preceded by an $\mathrm{r}$. This basic rS pattern was similar to that recorded in the right atrium in the region of the inferior vena cava and represented either right ventricular surface or cavity potential. The interfering $r^{\prime}$ which made the complex $\mathrm{W}$ shaped was derived from the left ventricular surface potential ( $r^{\prime}$ synchronous with $R$ of V5). Again, the $P$ wave at E1 was devoid of an intrinsic deflection which was present in the P wave at E3. The ventricular potential at this atrial level (E3) reflected left ventricular cavity potential (deep Q) (Fig. 2).
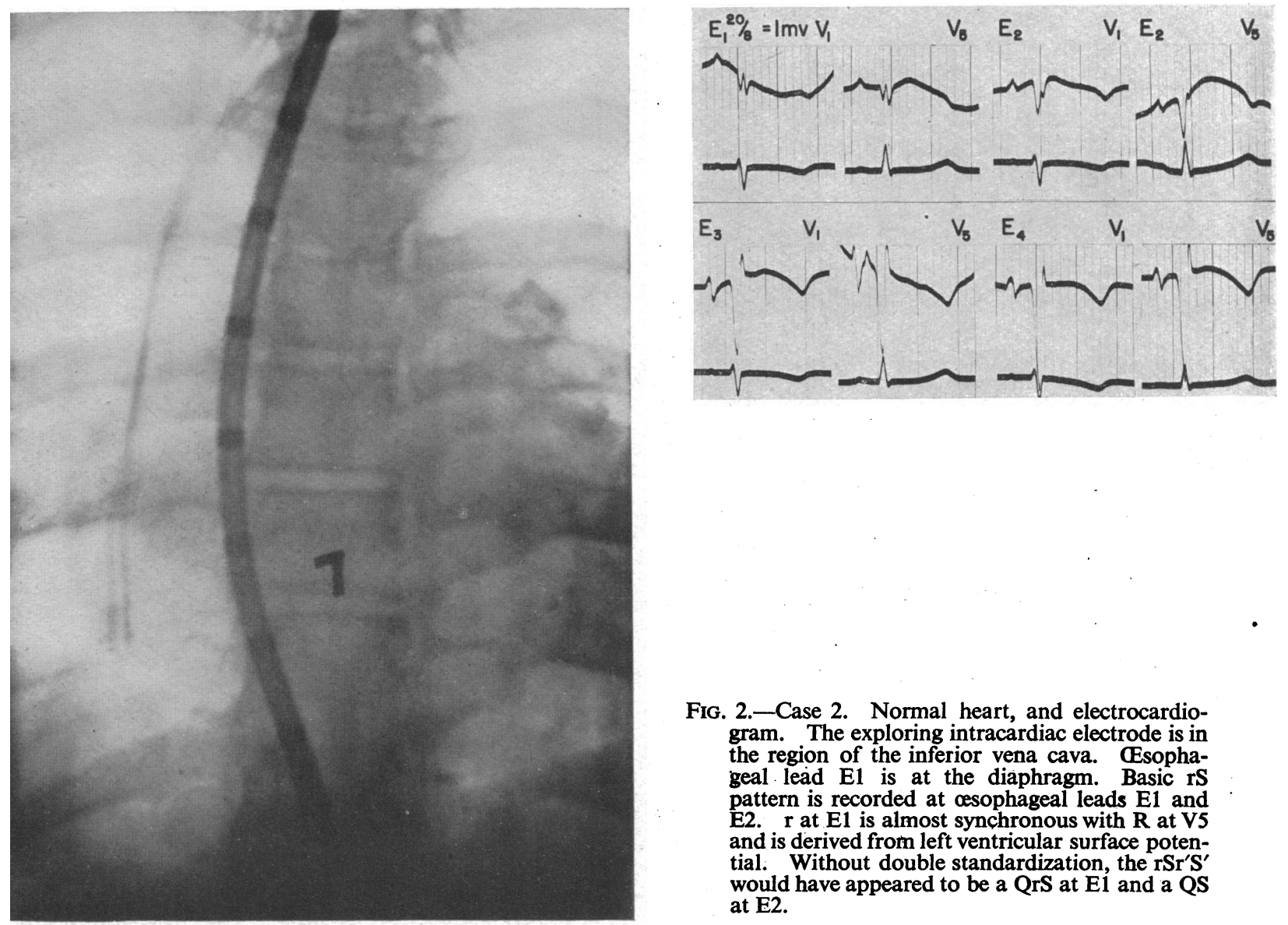

In this normal patient, the ventricular potential at $\mathrm{E} 1$ again did not resemble a left ventricular surface potential. It was a mixed potential similar to the one recorded in the right atrium in the region of the inferior vena cava. Here again the $r$ at E1 was recognized only because standardiza-

Fig. 2.-Case 2. Normal heart, and electrocardiogram. The exploring intracardiac electrode is in the region of the inferior vena cava. Esophageal lead $\mathrm{E} 1$ is at the diaphragm. Basic $\mathrm{rS}$ pattern is recorded at cesophageal leads E1 and E2. $r$ at $E 1$ is almost synchronous with $R$ at V5 and is derived from left ventricular surface potential. Without double standardization, the $\mathrm{rSr}^{\prime} \mathbf{S}^{\prime}$ would have appeared to be a QrS at E1 and a QS at E2. 
tion was doubled $(1 \mathrm{mv}=20 \mathrm{~mm}$.) and simultaneous reference leads were taken. Without these, the $\mathrm{rSr}^{\prime} \mathrm{S}^{\prime}$ at $\mathrm{E} 1 \mathrm{might}$ easily have been mistaken for a $\mathrm{W}$ shaped QS complex.

Case 3. A man, 47 years of age, had an electrocardiogram showing left axis deviation, S1, S2, and S3 being present. A broad $\mathrm{R}$ was recorded in aVR. At E1 $(1.75 \mathrm{~cm}$. below the diaphragm) an $\mathrm{rS}$ pattern was recorded. This pattern was also recorded at E2 and E3. The rS potential was similar to the potential recorded at the bottom of the right atrium. It represented right ventricular cavity or surface, and not left ventricular surface potential. The $P$ wave at E1 still showed an intrinsic deflection (Fig. 3).
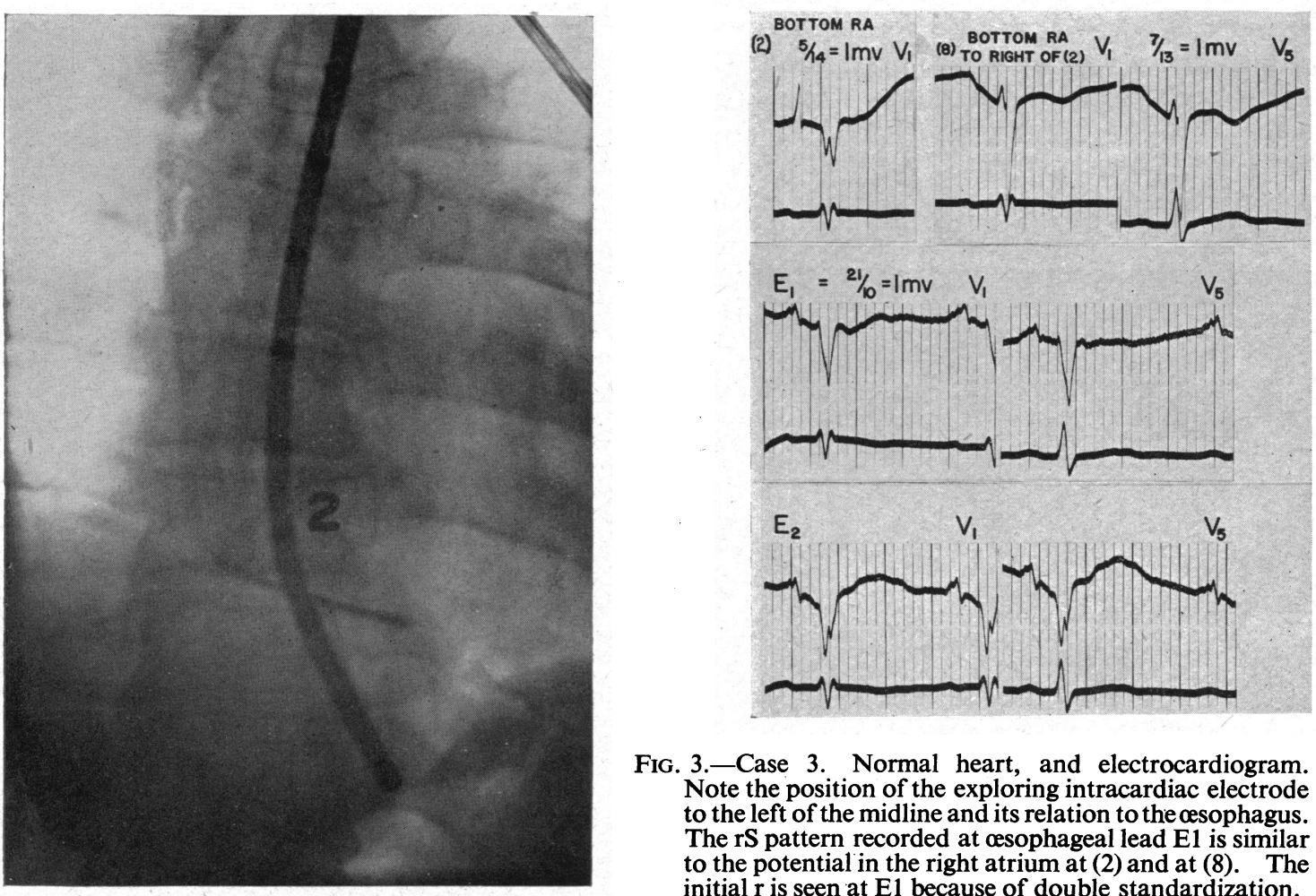

FIG. 3.-Case 3. Normal heart, and electrocardiogram. Note the position of the exploring intracardiac electrode to the left of the midline and its relation to the csophagus. The rS pattern recorded at osophageal lead E1 is similar to the potential in the right atrium at (2) and at (8). The initial $\mathrm{r}$ is seen at $\mathrm{E} 1$ because of double standardization.

In this normal patient, the exploring electrode in the right atrium extended past the mid-line. In the left oblique view the electrode was located posteriorly. The relationship of the exploring electrode in the right atrium to the œsophagus was clearly shown in the spot-film (Fig. 3). This close anatomical relationship of the right atrium to the œsophagus provided a basis for the similarity of potentials in the lower œsophagus and in the right atrium. It also accounted for the presence of an intrinsic deflection in the $P$ wave at E1, which was below left atrial levels. Furthermore, the initial $\mathrm{r}$ of the ventricular complex at $\mathrm{E} 1$ was visualized only because standardization was doubled $(1 \mathrm{mv}=20 \mathrm{~mm}$.). With normal standardization $(1 \mathrm{mv}=10 \mathrm{~mm}$.), the $\mathrm{r}$ would have been almost isoelectric. The rS could have been mistaken for a QS.

\section{Patient with Normal Heart and Partial Conduction Delay to the Right Ventricle}

Case 4. A boy, 14 years of age. There was right axis deviation and the QRS measured 0.09 sec. The somewhat delayed $R$ over the right side of the chest suggested a conduction delay to the right ventricle. At E1 (at the diaphragm) a QRS was recorded. The R at E1 was synchronous with the $\mathrm{R}$ at V5. The deep $\mathrm{Q}$ waves at E1, the bottom of the right atrium, and at V5 were synchronous. 


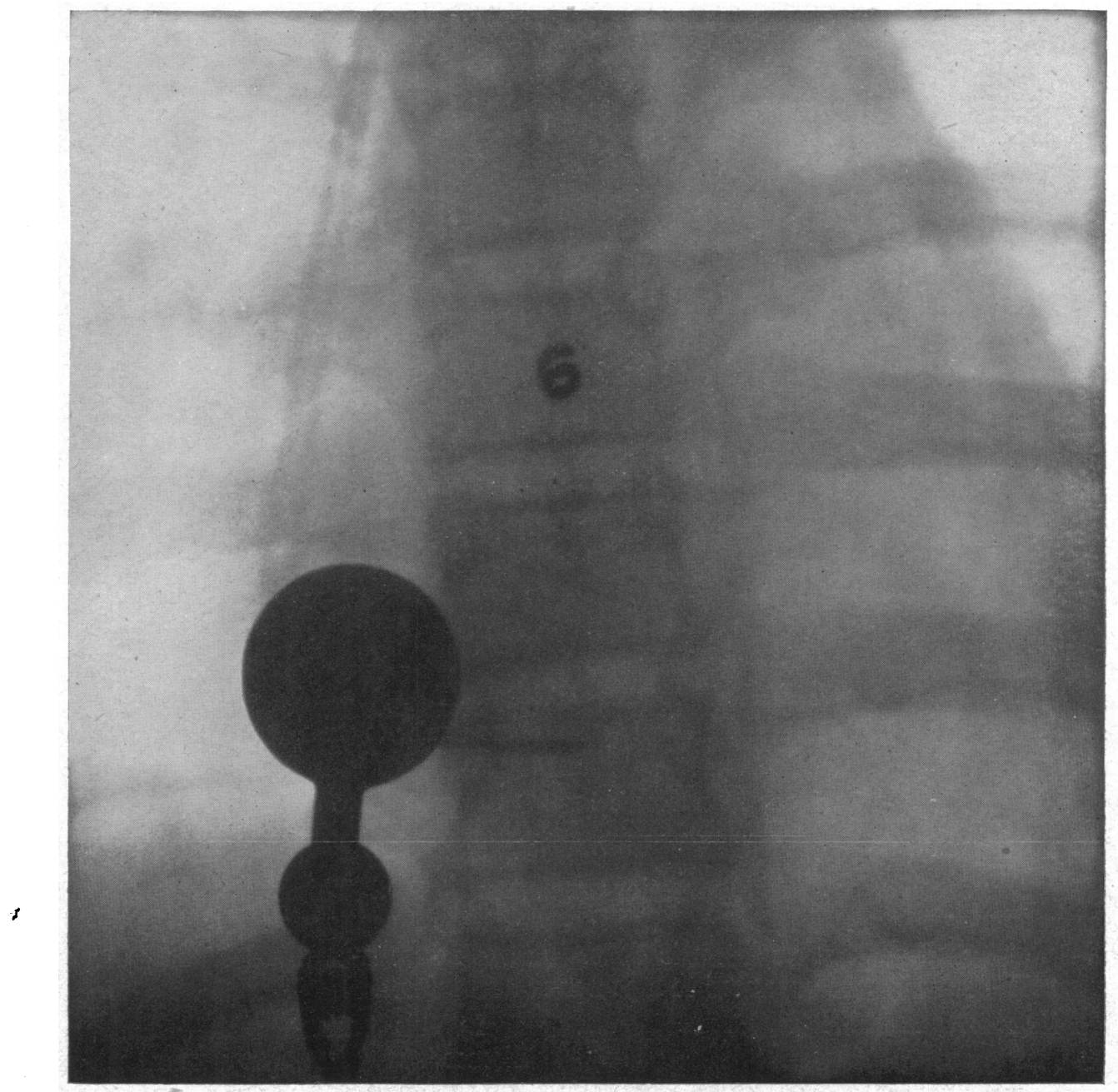

FIG. 4. - Case 4. Normal heart. The exploring intracardiac electrode is at the bottom of the right atrium. Record 6 (Fig. 5) was taken at this point.

The ventricular potential at E1 (QRS) was similar to the potential recorded in the bottom of the right atrium (Fig. 4 and 5) and both reflected left ventricular cavity and surface potentials.

In this patient, without heart disease, but with a mild right ventricular conduction delay, a $Q$ wave representing left ventricular cavity potential was recorded at the "ventricular level " (E1) and at the bottom of the right atrium. This $\mathrm{Q}$ wave at $\mathrm{E} 1$ most certainly was not a reflection of left ventricular cavity potential through a "window" of a posterior wall infarct. The $R$ wave at E1, although recorded at the "ventricular level" represented only a remnant of the left ventricular surface potential.

\section{Patients with Right Ventricular Hypertrophy}

Case 5. A man, 59 years of age. There was right axis deviation. A broad delayed $\mathbf{R}^{\prime}$ was recorded in aVR and over the right side of the chest. The ventricular complex at E1 $(1.75 \mathrm{~cm}$. below the diaphragm) consisted of a QRs. The P wave at E1 was tall and showed an intrinsic deflection. The ventricular potential at El (QRs) was similar to the potential recorded at the bottom 


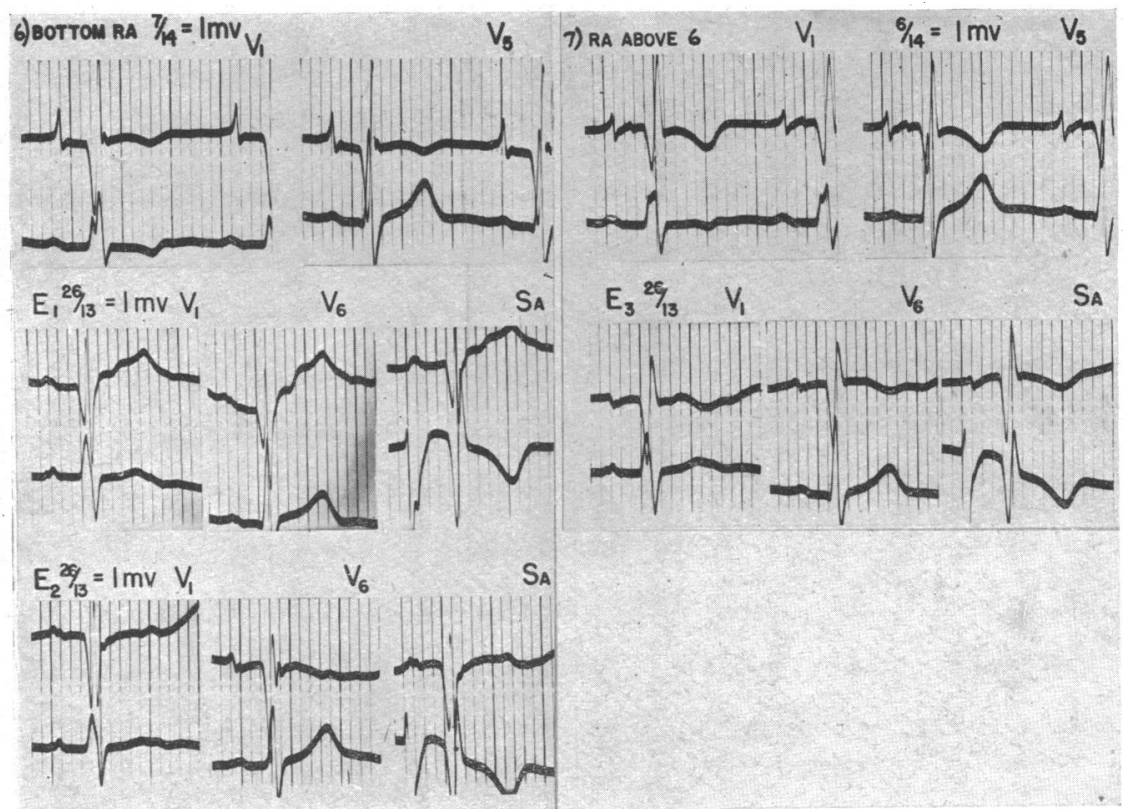

Fig. 5.-Case 4. Partial conduction delay in the right ventricle. The ventricular potentials at cesophageal leads E1 and E2 (QRS) are similar to those at the bottom of the right atrium (6). Esophageal lead E3 is similar to the intracardiac potential recorded in the right atrium (7) just above (6). The conduction delay to the right ventricle (tall $R-R^{\prime}$ at $V 1$ in records 6 and 7) was accentuated during intracardiac catheterization. The $Q$ wave at osophageal lead E1 is unrelated to posterior wall - infarction.

of the right atrium in the region of the inferior vena cava (Fig. 6). This pattern was also obtained at higher œsophageal levels (E2 to E6). The P wave at the "ventricular level " (E1), instead of being ill-defined, still showed an intrinsic deflection as it does over atrial levels. The $Q$ wave recorded at E1, certainly was unrelated to a posterior wall infarct.

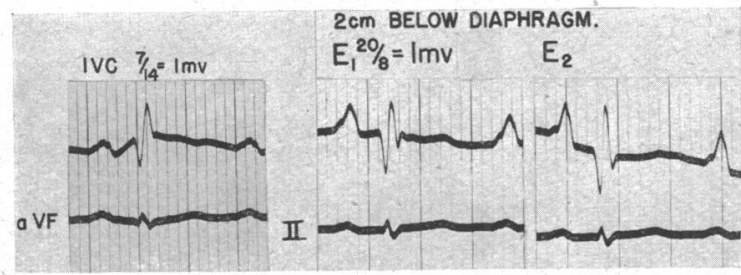

FIG. 6.-Case 5. Right ventricular hypertrophy. The QRs at œsophageal leads E1 and E2 are similar to the intracardiac potential recorded in the region of the inferior vena cava. The deep $Q$ wave is unrelated to posterior wall infarction. The $P$ wave at E1 still retains an intrinsic deflection.

In this patient, with pulmonary heart disease, spot-films clearly demonstrated that the catheter in the enlarged right atrium extended much to the left of the mid-line and overlapped the œsophagus. The posterior position of the catheter in the left oblique view corroborated the close relationship of the enlarged right atrium to the œsophagus. This finding provided an anatomical basis for the similarity of the cardiac potentials recorded in the lower end of the œsophagus and in the right atrium. The presence of an intrinsic deflection of the $P$ wave at $E 1$, presumably below left atrial levels, could also be explained by the close relationship of the right atrium to the œsophagus.

Case 6. A man, 58 years of age. There was right axis deviation. A broad delayed $R^{\prime}$ was recorded in aVR. The delayed $R^{\prime}$ over the right side of the chest was tall. The ventricular complex at E1 (at the diaphragm) consisted of a rSR's'. This potential was similar to the potential recorded at the bottom of the right atrium (Fig. 7). Similar potentials were recorded in the œsophagus at higher levels (E2 to E8). The rSR's' in all probability reflected a mixture of right ventricular cavity 


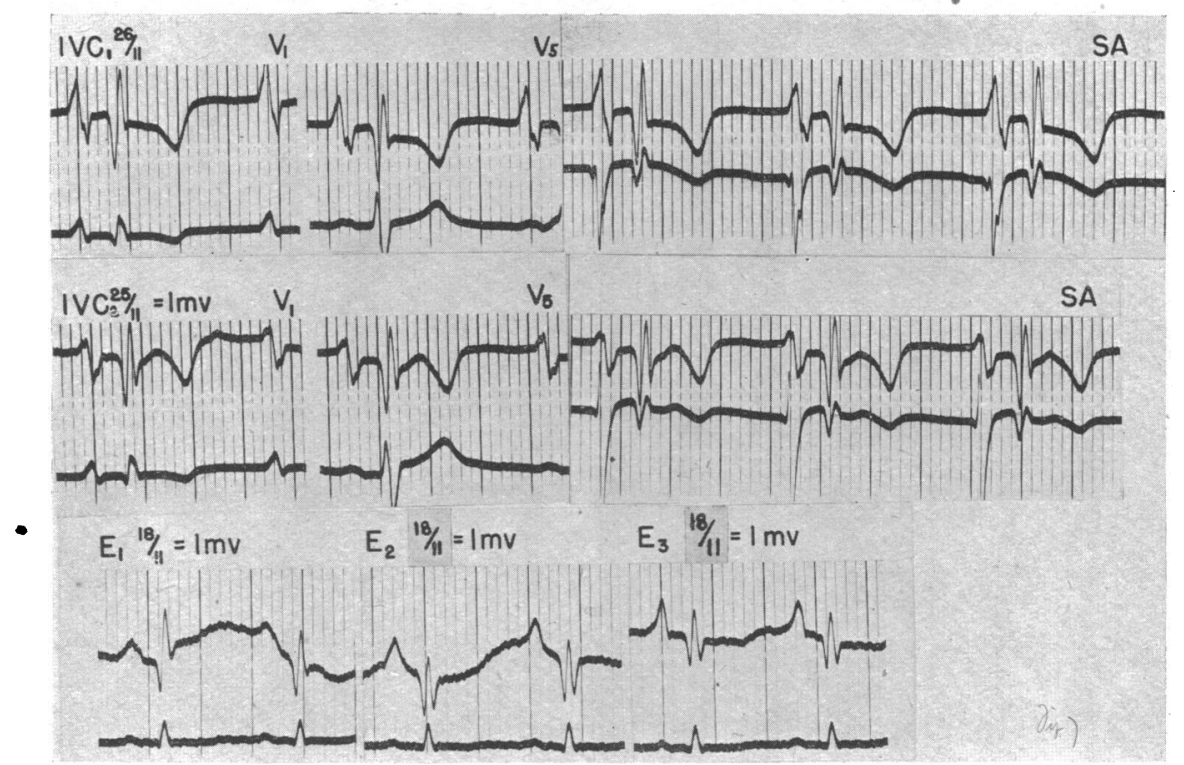

FIG. 7.-Case 6. Right ventricular hypertrophy. At osophageal lead E1 an rSR's' is obtained which is similar to the intracardiac potential recorded at the bottom of the right atrium in the region of the inferior vena cava. This mixed potential reflects right ventricular cavity and surface potential. With normal standardization the initial $\mathbf{r}$ would have been isoelectric and would have been misinterpreted as a $Q$ wave. The $P$ wave at $E 1$ still retains a sharp intrinsic deflection. IVC2 is at a slightly higher level than IVC1.

and surface potential. Without double standardization the initial $\mathrm{r}$ of this pattern would not have been recognized and the $S$ wave would have been misinterpreted as a $Q$ wave.

Case 7. A man, 46 years of age. Standard leads showed S1, S2 and S3. .A broad delayed R' was recorded at aVR and over the right side of the chest. At E1 (at the diaphragm) there was an apparent QS pattern, the upstroke of which was interrupted by an R. This potential was similar to that recorded at the inferior vena cava where an $\mathrm{rS}$ pattern was recorded. The rS pattern was a reflection of right ventricular cavity. At E1, the $P$ wave showed an intrinsic deflection (Fig. 8).

Once again in a patient with right ventricular hypertrophy, an apparent deep QS was recorded at E1. In reality this was an $\mathrm{rS}$, but despite maximum amplification, the initial $\mathbf{r}$ was inconspicuous because of its very. low voltage. Again, the type of $\mathbf{P}$ wave expected at higher atrial levels (with intrinsic deflection) was recorded at the "ventricular level."

Case 8. A man, 62 years of age. There was right axis deviation. The QRS complexes measured $0.09 \mathrm{sec}$; TII and TIII were inverted. The extremity leads were not remarkable. A qRs pattern was recorded over the right chest. There was no $Q$ wave over the left side of the præcordium. A QR pattern was recorded at E1 (at the diaphragm). This QR potential was similar to that recorded in the right atrium in the region of the inferior vena cava. At E3, the ventricular complex resembled that recorded in the right atrium at the tricuspid valve. Those $Q R$ potentials reflected a cavity $Q$ and a surface $R$. It was difficult to decide whether the $Q$ wave reflected right or left ventricular cavity, since no positive initial deflection was recorded in the right ventricular cavity. The absence of a $Q$ wave over the left præcordium made it likely that the $Q$ wave reflected right ventricular cavity (Fig. 9).

In this patient with right ventricular hypertrophy, a $Q$ wave was recorded at $E 1$ which was unrelated to posterior wall infarction. There was again evidence that the enlarged right atrium was in close relationship with the osophagus and that similar potentials were recorded both in the right atrium and in the œsophagus. 

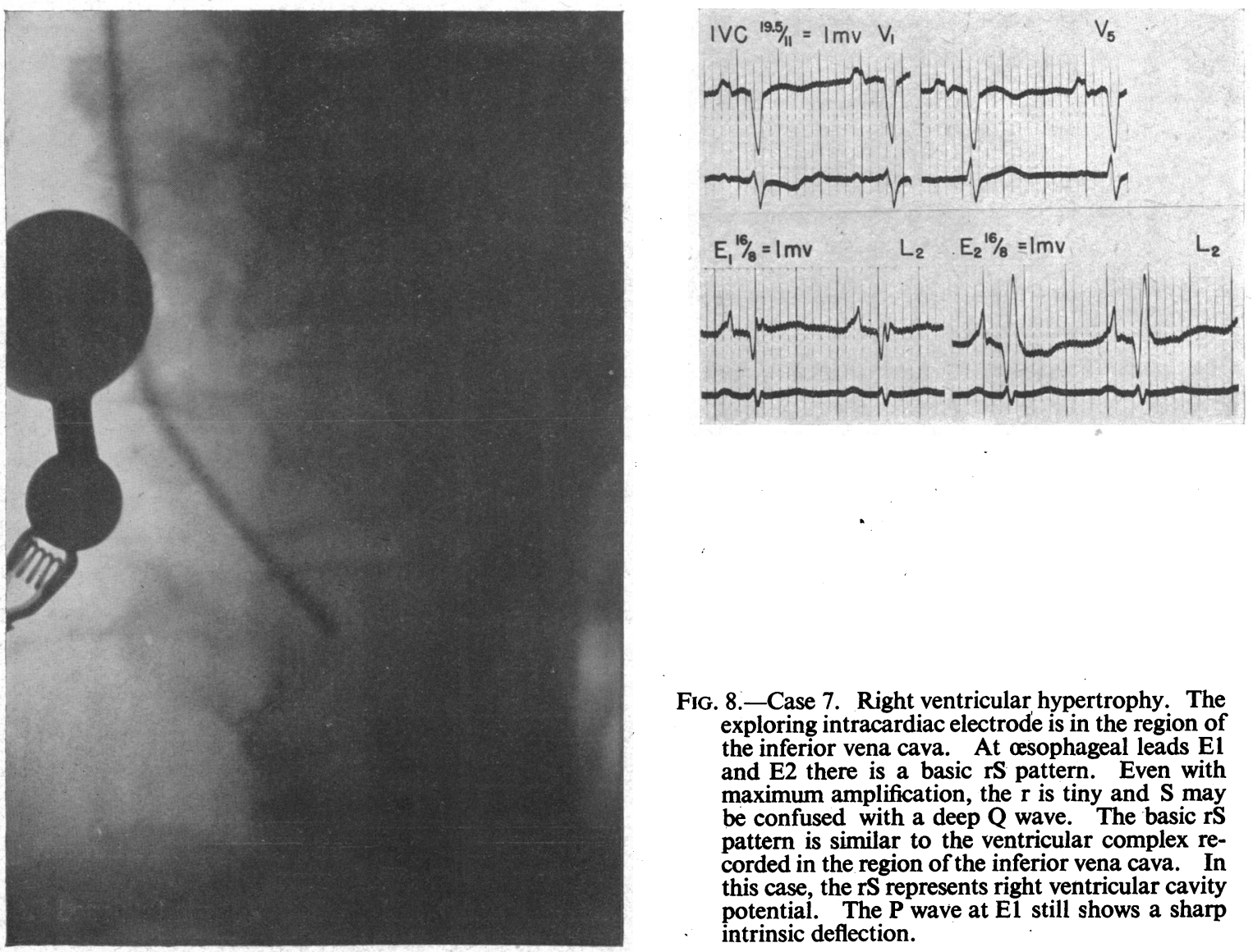

Fig. 8.-Case 7. Right ventricular hypertrophy. The exploring intracardiac electrode is in the region of the inferior vena cava. At œsophageal leads E1 and E2 there is a basic rS pattern. Even with maximum amplification, the $r$ is tiny and $S$ may be confused with a deep $Q$ wave. The basic rS pattern is similar to the ventricular complex recorded in the region of the inferior vena cava. In this case, the rS represents right ventricular cavity potential. The $P$ wave at $E 1$ still shows a sharp intrinsic deflection.

\section{Patient with Left Ventricular Hypertrophy}

Case 9. A man, 52 years of age. There was left axis deviation. The electrocardiogram was typical of left ventricular hypertrophy. At E1 (at the diaphragm), an rS pattern was recorded (Fig. 10).

In this patient, the influence of left ventricular surface was to the left arm and left axilla. The left ventricular surface did not influence the potential in the lower part of the esophagus. The rS at $\mathrm{E} 1$ reflected right ventricular cavity or surface potential.

\section{Discussion}

The intimate anterior relationship of the œsophagus with the left atrium below the tracheal bifürcation is well known and has been described by Quain (1882), Piersol (1930), Gray (1942), and Cunningham (1943). The æsophagus actually leaves the spine at the fifth thoracic vertebra to lie close to the left atrium (Evans, 1936). Although veering slightly to the left at the level of the seventh thoracic vertebra, the esophagus is still in close relationship anteriorly with the left atrium (Toldt, 1904; Eycleshymer and Schoemaker, 1911). From the eighth to the tenth thoracic vertebra, the œsophagus continues to the left and anteriorly to enter the abdomen through the diaphragm. This segment is actually the lower end of the œsophagus at the diaphragm, where the osophageal lead (E1) is positioned in the cases of our study. The normal left ventricle is usually not listed as an anterior relation of the œsophagus in this region according to the authorities mentioned above and 

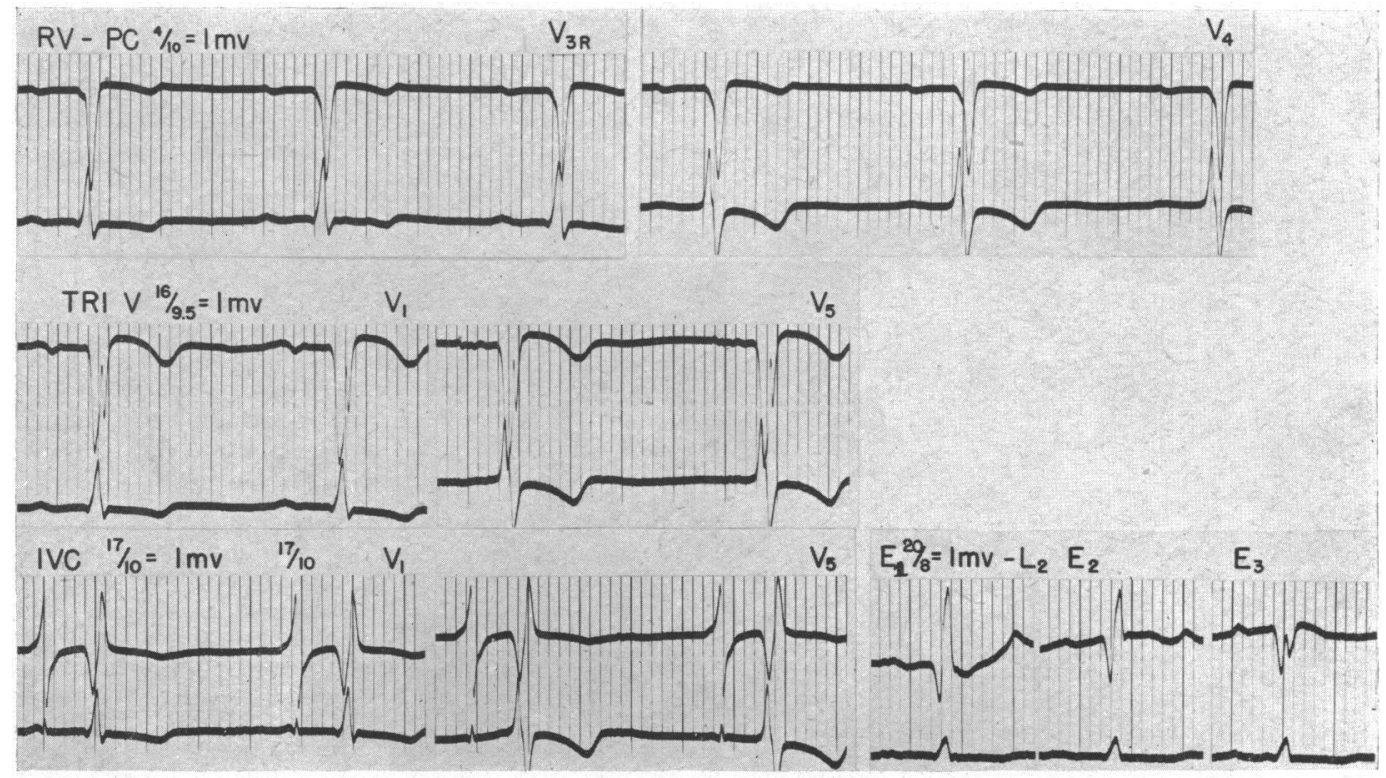

$E_{3}$

FIG. 9.-Case 8. Right ventricular hypertrophy. A QR pattern is obtained at œsophageal lead E1 which is similar to the intracardiac potential recorded in the region of the inferior vena cava. At the tricuspid valve region, there is a QS pattern similar to the pattern at E3, where the upstroke is interrupted by an $R$ wave. A QS is recorded in the cavity of the right ventricle. The $Q$ wave in osophageal leads is unrelated to posterior wall infarction.

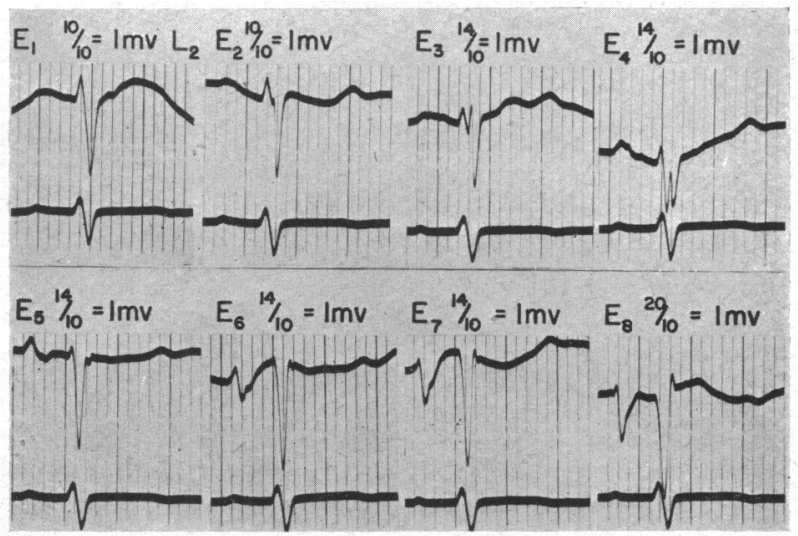

FIG. 10.-Case 9. Left ventricular hypertrophy. An rS pattern is recorded at œsophageal lead E1. The rS reflects right ventricular cavity or surface potential. $Q$ waves are recorded in the osophageal leads with the appearance of an intrinsic deflection in the atrial complexes.

to Evans (1936). However, Rigler (1929) maintains that the œsophagus is in contact with " a small portion of the left ventricle" for 2 to $3 \mathrm{~cm}$. above the diaphragm. Brown (1936) refers to the serial cross-sections of Eycleshymer and Schoemaker (1911) as anatomical proof that an electrode in the œsophagus at the diaphragm is " closer to the base of the left ventricle than is a præcordial lead to the surface of the right ventricle." Brown stresses this left-anterior relationship to the left ventricle, but only mentions the possibility of a right-anterior relationship of the œsophagus to the right atrium at the inferior vena cava.

Our findings seem to indicate that the relationship of the œsophagus to the right and anteriorly 


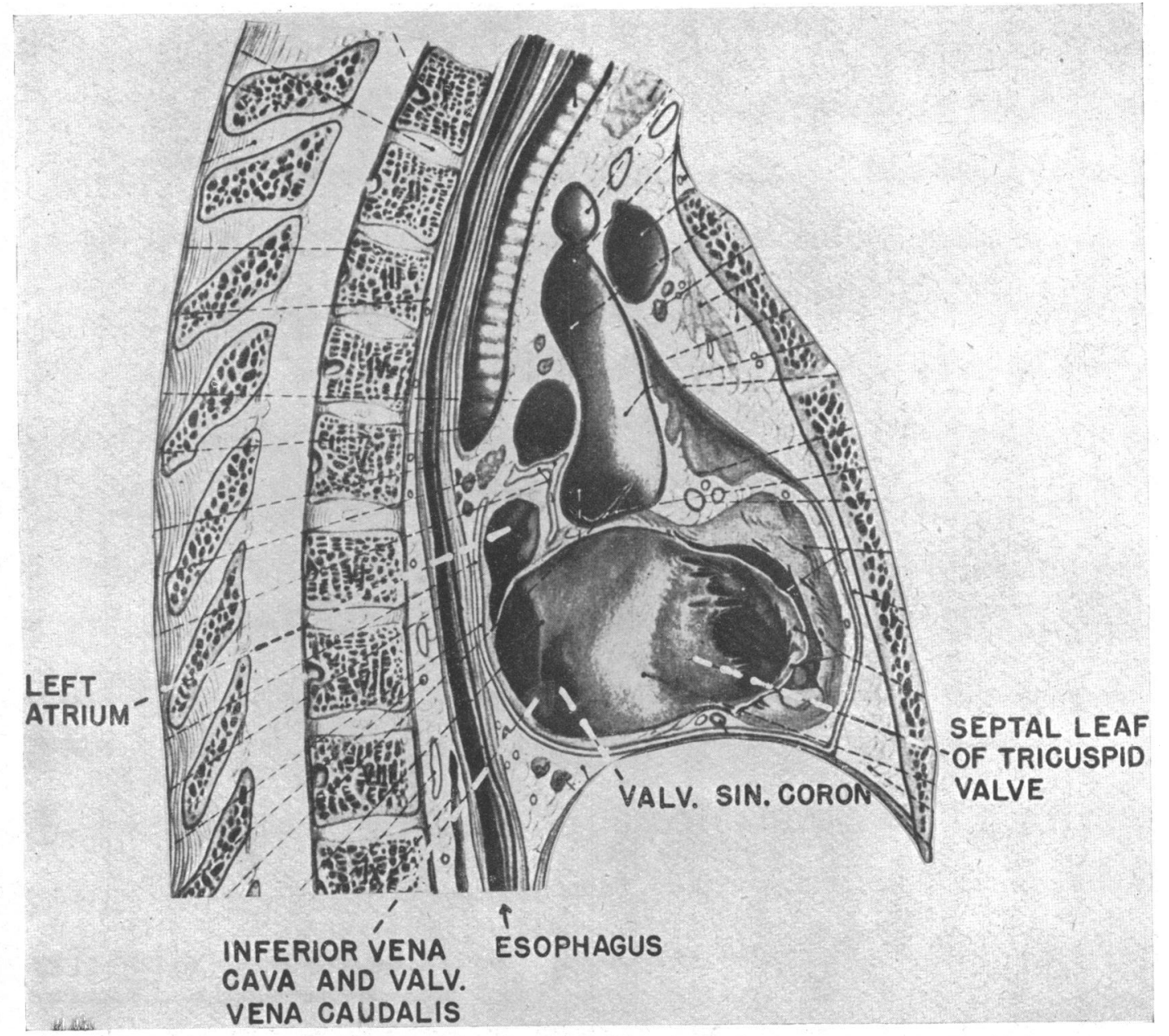

FIG. 11.-Median sagittal section of thorax (from Pernkopf).

with the inferior vena cava and at times with the right atrium is often important for the understanding of potentials obtained at the diaphragm. Both Eycleshymer and Schoemaker (1911), and Pernkopf (1937) clearly demonstrate in their cross-sections that, at the diaphragm, the close cardiac relationships of the osophagus to the right and anteriorly are (1) the atrio-ventricular groove and (2) the bottom of the right atrium in the region of the inferior vena cava (Fig. 11 and 12). The spot-films of Case 3 (Fig. 3) illustrate this point. These right anterior relationships seem to be predominant in our normal patients, who show similar potentials in the œsophagus at E1, and in the right atrium in the region of the inferior vena cava. In these selected normal patients, the influence of the free left ventricular surface on the ventricular complex is minimal. The factor of anatomical relationship to the right atrium is even more evident in the cases of pulmonary heart disease with right atrial enlargement. In Case 5, the spot-films of the position of the catheter indicate the extension of the enlarged right atrium posteriorly and to the left beyond the mid-line. The relationship of this leftposterior extension of right atrium to the lower end of the œsophagus explains the similarity of ventricular potentials obtained at $\mathrm{E} 1$ and at the bottom of the right atrium in the region of the inferior vena cava. The presence of an intrinsic deflection in the $\mathrm{P}$ wave at $\mathrm{E} 1 \mathrm{may}$ also be attributed to this close anatomical relationship. 


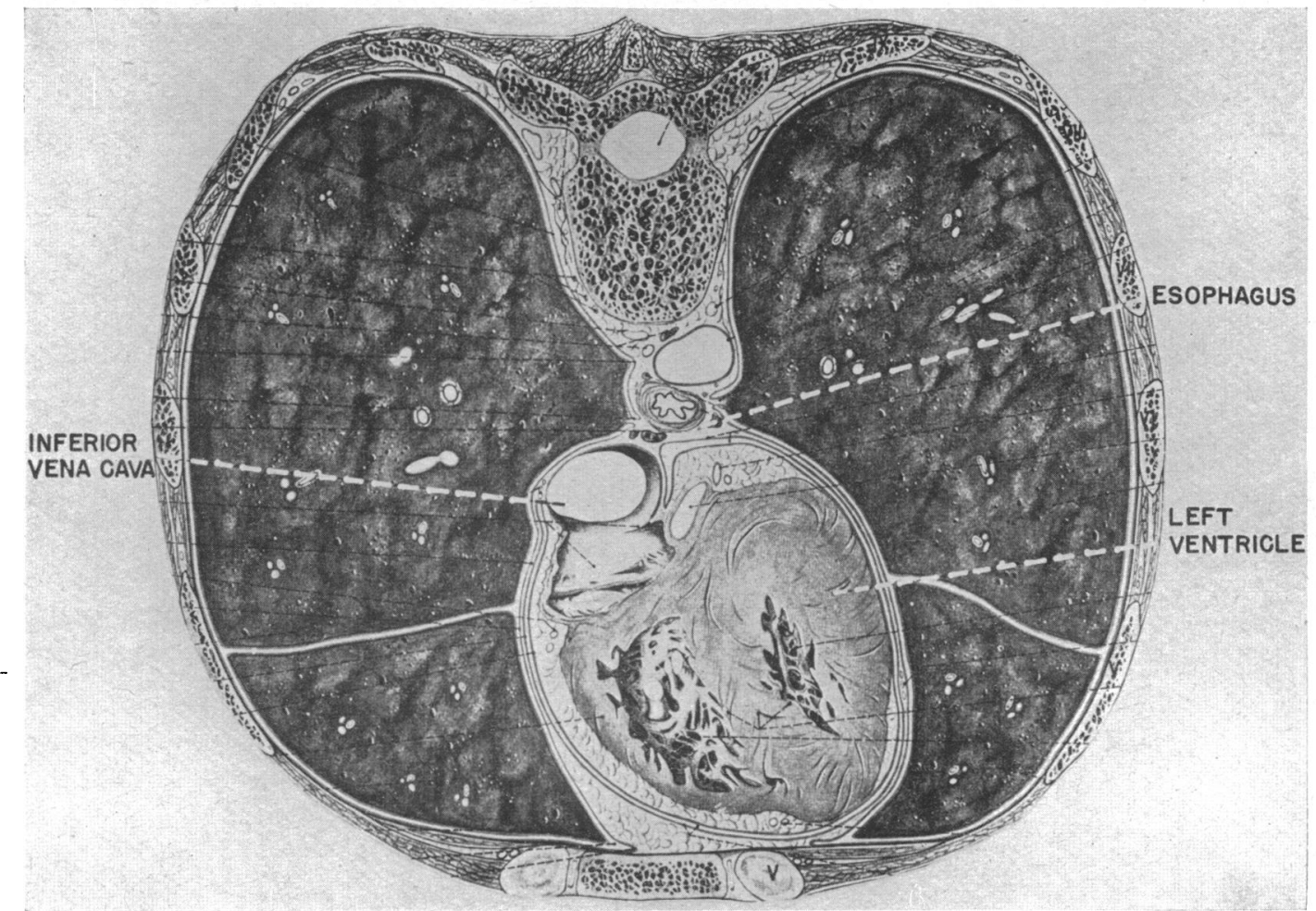

Fig. 12.-Cross-section of thorax at level of 9th thoracic vertebra (from Pernkopf).

The variability of the ventricular potential in the œsophagus at the diaphragm is common. When the ventricular potential does not reflect the free left ventricular surface (qRs), it may reflect either right ventricular surface or cavity (rS), and at times left ventricular cavity (QS) without the " window" effect of an infarct. In order to detect an initial $r$ wave and to avoid confusion with a $\mathrm{Q}$ wave, adequate amplification of the œsophageal potential is necessary. As a further precaution, præcordial reference leads (V1 and V5) should be recorded simultaneously with œsophageal leads.

\section{SUMMARY AND CONCLUSIONS}

- The ventricular potential at the diaphragmatic level of the œsophagus, the so-called "ventricular level," may not reflect free left ventricular surface (qRs), as has been assumed in the past.

The variability of ventricular potentials at the diaphragmatic level of the esophagus (E1) has been illustrated in a selected series of patients with (1) normal electrocardiograms, (2) normal heart with partial conduction delay to the right ventricle, (3) right ventricular hypertrophy, and (4) left ventricular hypertrophy. These potentials were either rS or QS in type and were similar to the potentials recorded in the right atrium at the inferior vena cava.

There is a close anatomical relationship of the diaphragmatic segment of the œsophagus, anteriorly and to the right, with the right atrium in the region of the inferior vena cava. This relationship is even more accentuated in the presence of right atrial enlargement, as in pulmonary heart disease or congestive failure. This anatomical relationship is the ætiological factor underlying the similarity of potentials recorded at $\mathrm{E} 1$ and in the right atrium at the inferior vena cava. 
These potentials may reflect surface or cavity of the right ventricle (rS). At times, left ventricular cavity (QS) is tapped without the presence of posterior wall infarction.

Simultaneous præcordial reference leads and adequate amplification are necessary in order to determine the presence of an initial $\mathrm{r}$ wave at $\mathrm{E} 1$ and so to avoid the misinterpretation of a $\mathrm{Q}$ wave.

\section{REFERENCES}

Brown, W: H. (1936). Amer.'Heart J., 12, 1.

Burchell, H. B. (1948). Amer. J. med. Sci., 216, 492.

Cunningham, D. J. (1943). Textbook of Anatomy, 8th ed. Oxford University Press, London.

Evans, W. (1936). The Course of the OEsophagus in Health, and in Disease of the Heart and Great Vessels. Great Britain Privy Council, Med. Res. Council, Spec. Rep. Series No. 208.

Eycleshymer, A. C., and Schoemaker, D. M. (1911). A Cross-Section Anatomy, Sec. 25-27, D. Appleton and Co., New York.

Gray, H. (1942). Anatomy of the Human Body, 24th ed. Lea and Febiger, Philadelphia.

Hamilton, J. G. M., and Nyboer, J. (1938). Amer. Heart J., 15, 414.

Helm, J. D. Jr., Helm, G. H., and Wolferth, C. C. (1944). Ibid., $27,755$.

Lieberson, A., and Liberson, F. (1934). Proc. Soc. exp. Biol., N.Y., 31, 441.

Nyboer, J. (1939). J. Clin. Invest., 18, 495.

(1941). Amer. Heart J., 22, 469.

Pernkopf, E. (1937). Topographische Anatomie des Menschen, Urban and Schwarzenberg, Vol. 1, Berlin and Vienna.

Piersol, J. A. (1930). Human Anatomy, J. B. Lippincott and Co., Philadelphia and London.

Quain, R. (1882). Elements of Anatomy, 9 th ed. William Wood and Co., New York.

Rigler, L. G. (1929). Amer. J. Roentgen., 21, 563.

Toldt, C. (1904). An Atlas of Human Anatomy for Students and Physicians, Rebman, Ltd. 